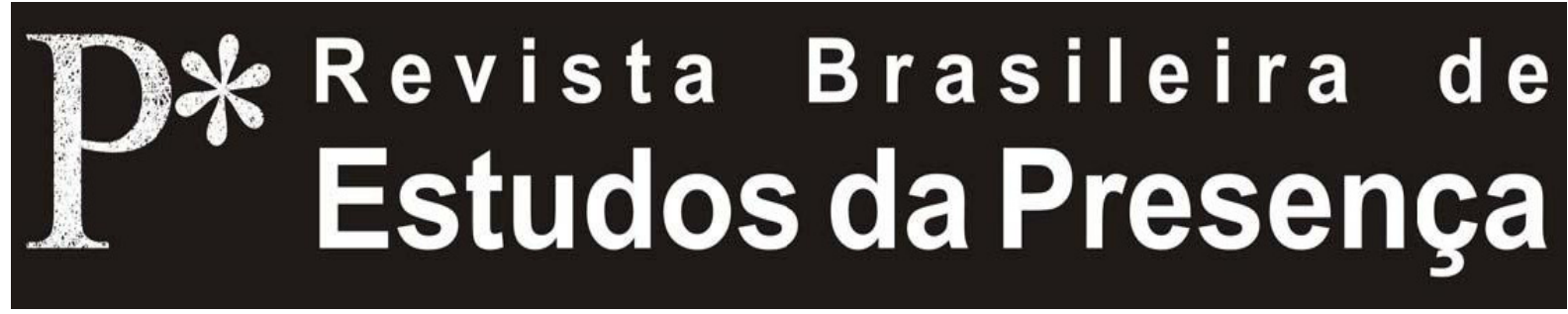

DOI - http://dx.doi.org/10.1590/2237-266035289

ISSN 2237-2660

\title{
Brook avec Grotowski: testemunho da vida e da arte de um certo polonês
}

Resenha sobre a obra

BROOK, Peter. Avec Grotowski. Brasília: Teatro Caleidoscópio \& Editora Dulcina, 2011.

Larissa Elias

Universidade Federal do Rio de Janeiro - UFRJ, Rio de Janeiro, Brasil

RESUMO - Brook avec Grotowski: testemunho da vida e da arte de um certo polonês -Avec Grotowski é uma coletânea de artigos, entrevistas e relatos de memória de Peter Brook a respeito do encenador polonês Jerzy Grotowski, que dá conta desde os primeiros encontros entre os dois artistas, em meados dos anos 1960, até reflexóes de Brook posteriores à morte de Grotowski, em 1999. Nos textos, evidencia-se o aspecto testemunhal, de alguém - Brook -, que acompanhou de perto o percurso de um artista - Grotowski -, que se encarregou de protegê-lo e de difundir sua obra. Trafegando entre a reverência e a elucidação da obra, Brook sinaliza, ao longo de seus testemunhos, para uma possível compreensão da peculiar trajetória de Jerzy Grotowski.

Palavras-chave: Grotowski. Ryszard Cieslak. Peter Brook. Teatro Sagrado. Arte como Veículo.

ABSTRACT - Brook avec Grotowski: testimony of life and art of a certain Pole - Avec Grotowski is a collection of articles, interviews and memories of Peter Brook about the Polish director Jerzy Grotowski, comprising from the first encounters of the two artists in the mid-1960s, to Brook's reflections after Grotowski's death in 1999. The texts emphasize the character of testimony, from someone - Brook -, who has closely followed the route of an artist - Grotowski -, who undertook to protect him and to disseminate his work. Walking between reverence and the elucidation of the work, Brook signals, along their testimonies, to a possible understanding of the peculiar trajectory of Jerzy Grotowski. Keywords: Grotowski. Ryszard Cieslak. Peter Brook. Holy Theatre. Art as a Vehicle.

RÉSUMÉ - Brook avec Grotowski: témoignage de la vie et de l'art d'un certain polonais - Avec Grotowski est une compilation d'articles, d'interviews et de témoignages de Peter Brook sur le metteur en scène polonais Jerzy Grotowski, rendant compte des premières rencontres entre les deux artistes dans les années 1960, jusqu'aux réflexions de Brook après la mort de Grotowski en 1999. Sous la forme de témoignages, les textes mettent en évidence le point de vue de quelqu’un - Brook - ayant suivi de près la carrière d'un artiste - Grotowski - et qui a été chargé de protéger et de diffuser son travail. Entre vénération et élucidation de l'œuvre, Brook propose, au cours des témoignages, sa conception de la trajectoire particulière de Jerzy Grotowski.

Mots-clés: Grotowski. Ryszard Cieslak. Peter Brook. Théâtre Sacré. L’Art comme Véhicule. 
Como esquecer a noite em que, saindo de um ensaio no Bouffes du Nord, eu reconheci Jerzy, que esperava no hall? [...] Como esquecer a foto de Jerzy com uma rosa na mão para receber Brook em sua chegada à Polônia em meados dos anos 1960? Como esquecer Peter e Jerzy juntos em Taormina? (Banu, 2011, p. 08).

Frases de Georges Banu, testemunha dos testemunhos de Brook, testemunha ocular e afetiva desta história de arte e de amizade, que costurando uma série de imagens retrata em seu Prefácio para o livro Avec Grotowski um pouco do que ele mesmo viu e nos conta como surgiu a ideia de publicá-lo. "Como salvar a marca desta amizade pontuada por tantos gestos, tantos textos" (Banu, 2011, p. 08), Banu se perguntava. A proposta foi feita por Banu a Brook num ônibus que os conduzia, juntamente com Grzegorz Ziólkowski, diretor de programação do Instituto Jerzy Grotowski, a Wroclaw.

Em 2007, sob a direção de Georges Banu e Ziólkowski, foi publicada em polonês a primeira versão do livro, sob o título Teatr jest tylko forma, o Jerzym Grotowskim. Em 2009 foi publicada a versão em inglês também sob a direção de Banu e Ziólkowski, mais Paul Allain, sob o título Theatre is just a form, on Jerzy Grotowski. A versão francesa, ao que parece, foi lançada simultaneamente à versão em inglês (pois ambas datam de janeiro de 2009). De acordo com nota na versão francesa, o artigo Testemunhos sobre Ryszard Cieslak não faz parte das versóes polonesa e inglesa.

Sáo quinze textos, entre relatos de memória, entrevistas, ensaios reflexivos, conferências etc., reunidos neste Avec Grotowski, além do anexo Diálogo entre Brook e Grotowski, mediado por Georges Banu, do Prefácio de Georges Banu, e ainda de uma cronologia e das referências das fontes dos textos, as duas organizadas por Grzegorz Ziólkowski. $\mathrm{Na}$ edição brasileira há também um Posfácio escrito pela diretora de teatro Celina Sodré, uma das tradutoras do livro para o português.

Os quinze textos são de natureza e procedência diversas, produzidos em diferentes contextos, "escritos ao longo de toda uma vida" (Banu, 2011, p. 08). Não há entre eles uma lógica de ordenação pautada por cronologia ou temática, mas todos carregam a marca do testemunho.

Alguns são extratos dos já bastante conhecidos livros de Peter Brook $O$ teatro e seu espaço ${ }^{1}$, $O$ ponto de mudança e Fios do tempo. São os casos, respectivamente, de $O$ teatro sagrado, Artaud e o grande quebra-cabeça, e Mártir e contador. Outro conhecido é o artigo in- 
titulado Grotowski, publicado primeiramente no Flourish, jornal da Royal Shakespeare Theatre Club, em 1966, usado em seguida como Prefácio de Em busca de um teatro pobre, de Grotowski e, posteriormente, corrigido, publicado em $O$ ponto de mudança.

As maiores novidades talvez sejam os textos-entrevistas-conferências-intervençôes de Brook, aos quais temos acesso pela primeira vez em português e que guardam ainda a potência das falas feitas ao vivo. Como a Apresentação do filme Akropolis, de 1968; a Apresentação do filme With Jerzy Grotowski, de 1980; o Discurso de abertura da conferência 'Tender para a essência', de 2005, texto baseado nos discursos de abertura de outra conferência, dedicada a Gurdjieff, realizada em 2001; Para ir além do teatro, versão abreviada de uma entrevista de Brook para o documentário Jerzy Grotowski - proba portretu (Jerzy Grotowski - tentativa de retrato), de 1999. Assim como uma curiosa Carta de recomendação que Brook faz para apresentar Grotowski a um professor da Universidade da Califórnia, com o objetivo de que Grotowski fosse convidado a participar de um programa de pesquisa.

Além destes, outros escritos inéditos em português, merecem atenção. Particularmente dois, sobre o ator Ryszard Cieslak. Testemunhos sobre Ryszard Cieslak, de 1992², e Uma sensibilidade absoluta, entrevista de 1993. São bastante escassas as informaçóes e as referências bibliográficas sobre Cieslak. Para a nossa alegria, há alguns vídeos, disponíveis na rede, nos quais temos a grata oportunidade de assisti-lo e, assim, de nos regenerar (falo do caráter regenerador a que se referia Bakhtin com relação ao riso) (Bakhtin, 1993). Os depoimentos de Brook despertam ainda mais fortemente em nós o nostálgico desejo de ter visto Cieslak atuar, de des-cobrir esse território ainda obscuro, que parece se iluminar aos pedaços e vagarosamente.

A um ponto da entrevista, em que relata a demonstraçáo de exercícios que Cieslak fizera e depois ensinara aos seus atores (atores da Royal Shakespeare Company, que Brook dirigia na época, 1966, e com os quais preparava o espetáculo US), Brook diz:

Desde o começo, Cieslak era nossa ligação com Grotowski. [...] Nós poderíamos dizer que Grotowski tocava os atores via Cieslak, que era de alguma maneira a expressão física dos seus pensamentos. Eles eram, por assim dizer, como um ser desdobrado (Brook, 2011, p. 40).

Em suas palavras, não se pode negar, há como que um encantamento. Note-se ainda como ele descreve o ator: "[...] esse corpo 
admiravelmente desenvolvido, esse rosto impactante, esse olhar modesto e atento que tinha Ryszard Cieslak" (Brook, 2011, p. 40).

Interessante também o que fala Brook sobre o primeiro encontro de seus atores com Grotowski e Cieslak.

[...] Grotowski estava lá [na sala], o ar sério, e ele disse algo particularmente surpreendente para os atores ingleses: "Deixem tudo que vocês têm do outro lado da porta. Náo tragam nenhuma bolsa, jornal, cachimbo, cigarro, nada de exterior deve entrar na sala de ensaio. Deixem lá fora todas as roupas que não são necessárias. Entrem de pés descalços [...]" (Brook, 2011, p. 39).

Se hoje pode nos parecer trivial, já incorporado, é porque perdemos a dimensão do impacto que isso representava naquela época. Para Brook e para os atores ingleses da Royal Shakespeare era uma inteira novidade. Assim como não temos mais a concreta dimensão do impacto causado pela apresentaçáo de $O$ príncipe constante, em Paris, que Brook assistira naquele mesmo ano de 1966.

É dessa natureza íntima que nascem os melhores e mais calorosos testemunhos de Peter Brook.

A montagem do Principe acabaria por se tornar uma espécie de marca do teatro de Grotowski e carregaria atrás de si, e quase que indistintamente, uma série de nomes-emblemas como ator santo, ato total, autopenetração, via negativa, só para citar alguns.

Outros artigos incluídos no livro como Qualidade e artesanato, intervenção de Brook durante o Colóquio Os Pensadores do Ensinamento, realizado no ano 2000, e Grotowski era..., texto em forma de carta, escrito a um jornal boliviano, em 1999, dáo conta de importantes questóes, recorrentes na produção ensaística de Brook, acerca dos legados, não só de Grotowski, mas de Constantin Stanislavski e de Vsevolod Meyerhold, de Antonin Artaud, de Max Reinhardt (hoje totalmente esquecido, nos avisa Brook) e de Gordon Craig, das possibilidades de ensinamento e de aprendizado, e das possibilidades de ultrapassagem.

"Meyerhold contava que, durante os ensaios, Stanislavski não parava de repetir: 'Não é isto, não estou convencido'” (Brook, 2011, p. 71), cita Brook, dizendo que estas foram as duas frases que mais ajudaram aos atores de Stanislavski. E, mais a frente, continua "O que Stanislavski dizia - 'Náo é isto, busquem em vocês mesmos' -, é inseparável de Grotowski que observava cada detalhe e detectava a mínima mentira, falta de precisão ou de 'engajamento de verdade" (Brook, 2011, p. 72). 
São as imitaçóes canhestras que fazemos deles, assim como as inspiraçóes intensas que eles nos trazem, o que estimula Brook a nos indagar:

Qual a nossa relação com todas essas magníficas tentativas? Para onde elas nos conduzem? Como aproveitar este trabalho sabendo que a imitação é a pior das coisas, uma verdadeira profanação? Se o teatro é algo vivo, a imitação é quem sufoca o fluxo da vida, que a congela. É o paradoxo da forma, tão indispensável e tão frequentemente cadáver do impulso vivo. A questão seguinte é posta: como acolher, no sentido "vivo" do termo, tudo aquilo que é tradicional, como receber aquilo que remonta a uma corrente do passado, sem, no entanto, ressecá-lo? (Brook, 2011, p. 69).

Como absorver outras experiências na nossa própria sem engessá-las? Talvez mantendo vivas as indagaçóes. Não se pode deixar de ver um certo purismo na afirmação de Brook. Imitar pode ser um caminho para um começo. Há uma imitação cega, e uma outra consciente e inquieta. A imitaçáo tem sentidos, me parece, mais complexos do que o que lhe atribui Brook.

Do mesmo modo, seu testemunho direto e íntimo adquire, por vezes, um viés simplificador. Algumas ideias perpassam aqui e ali quase todos os textos: a ideia da arte como veículo (explicitada no título de um dos artigos que integram o livro: Grotowski, a arte como veículo), a ideia de que há um interior, e de que há, portanto, uma busca desse interior; em consequência, a ideia de que há um des-velamento, e associada a ela uma certa ideia de essência. Dessas ideias, e da maneira como Brook as articula, emerge um Grotowski reto, puro, especial, mitico, quase santo.

O comentário de Richard Schechner, citado por Celina Sodré, em seu Posfácio, sobre a metanoia (mudança de aparência física) de Grotowski reforça essa imagem mítica. De acordo com a tradutora, Schechner diz que "[...] antes da mudança era como se ele estivesse disfarçado, como se as reviravoltas de seu percurso fossem se refletindo na sua aparência" (Schechner apud Sodré, 2011, p. 99). Que as reviravoltas se refletissem na aparência, que a aparência e tudo mais se transformassem, mas disfarçado? Antes entáo, ele não era ele? $\mathrm{Ou}$ o verdadeiro ele estava guardado no interior e se exteriorizou? Ele teria chegado a uma espécie de essencialidade de si? Tal perspectiva descartaria outras possibilidades do ser, como se não existissem facetas ou contradições. 
É curiosa a comparação que Banu faz entre a amizade de Peter Brook e Jerzy Grotowski e a de Constantin Stanislavski e Vsevolod Meyerhold.

Brook protegeu Grotowski assim como Stanislavski protegera Meyerhold. Foram atos de amor.

Mas havia entre Meyerhold e Stanislavski, a meu ver, sem que isso afetasse a admiração de um pelo outro, um diálogo mais despudorado, mais aberto, mais crítico, mais inquieto, assim como o que havia entre eles e Anton Tchekhov.

O diálogo entre Brook e Grotowski, que é menos diálogo, e é mais testemunho de Brook sobre Grotowski, assume um ponto de vista mais unívoco: o da reverência e o da admiração, incondicionais.

Quando Brook se distingue mais firmemente de Grotowski, como no artigo $O$ teatro é um dominio da vida, em que fala do abandono do público por Grotowski, e da necessidade, dele Brook, dessa energia - o encontro entre atores e público - que faz nascer o espetáculo, e afirma "[...] isso, para mim, é todo o teatro" (Brook, 2011, p. 78), esse momento os torna, por assim dizer, mais terrenos.

Náo que se deva rejeitar o sagrado, mas para citar o próprio Brook, náo devemos nos demorar demais em um só lugar. Shakespeare, também por este motivo, por trafegar entre esses mundos sagrado e profano, livre e abusadamente, se tornou para Brook uma espécie de paradigma da variedade humana.

O anonimato que, de certo modo, é reivindicado por Grotowski, quando diz que o autor da Bíblia é o Espírito Santo e que "[...] no ápice da criatividade, mesmo se ela não é anônima, existe uma força impessoal" (no anexo Diálogo entre Peter Brook e Jerzy Grotowski, que se segue ao último texto de Brook) (Grotowski, 2011, p. 93-94), fica, ao fim da leitura, quase esquecido. Provavelmente sem esse objetivo, Brook ressalta o autor Grotowski e reforça o mito. Felizmente o Diálogo vem depois do último texto (colocado nesta posição por uma questão de ordem, já que é um anexo), funcionando, à moda Brook, como uma espécie de quebra e de retorno ao chão.

O livro gera duas impressóes distintas, e não importa se o leitor é um leigo ou um iniciado, um jovem ou um experiente artista ou ainda um pesquisador idem idem.

Uma colabora para a construção e a solidificação de um mito. A outra nos inspira, pelos sinais que Brook emite. Pistas para entrever, para atravessar os tantos caminhos que Grotowski abriu, para aproveitar as chances que ele continua nos oferecendo. 


\section{Notas}

${ }^{1} \mathrm{O}$ título original de $O$ teatro e seu espaço é The empty space ( $O$ espaço vazio).

${ }^{2}$ Texto extraído do livro Ryszard Cieslak, acteur embleme dês années soixante, obra coletiva organizada por Georges Banu.

\section{Referências}

BAKHTIN, Mikhail Mikhailovitch. A Cultura Popular na Idade Média e no Renascimento: o contexto de François Rabelais. São Paulo: HUCITEC; Brasília: Editora da Universidade de Brasília, 1993.

BANU, Georges. Ryszard Cieslak, Acteur Embleme dês Années Soixante. Arles: Actes Sud-Papiers, 1992.

BANU, Georges. Prefácio: o livro de uma vida. In: BROOK, Peter. Avec Grotowski. Brasília: Teatro Caleidoscópio \& Editora Dulcina, 2011. P. 07-13.

BROOK, Peter. O Teatro e seu Espaço. Petrópolis: Editora Vozes, 1970.

BROOK, Peter. O Ponto de Mudança: quarenta anos de experiências teatrais: 1946-1987. Rio de Janeiro: Civilizaçáo Brasileira, 1994.

BROOK, Peter. Fios do Tempo. Rio de Janeiro: Bertrand Brasil, 2000.

BROOK, Peter. Avec Grotowski. Brasília: Teatro Caleidoscópio \& Editora Dulcina, 2011. GROTOWSKI, Jerzy. Em Busca de um Teatro Pobre. Rio de Janeiro: Civilização Brasileira, 1987.

GROTOWSKI, Jerzy. Diálogo entre Peter Brook e Jerzy Grotowski, mediado por Georges Banu. In: BROOK, Peter. Avec Grotowski. Brasília: Teatro Caleidoscópio \& Editora Dulcina, 2011. P. 79-96.

SODRÉ, Celina. Posfácio à edição brasileira: Grotowski était un mystique! In: BROOK, Peter. Avec Grotowski. Brasília: Teatro Caleidoscópio \& Editora Dulcina, 2011. P. 97-100.

Larissa Elias é professora e pesquisadora do curso de Artes Cênicas da Escola de Belas Artes da Universidade Federal do Rio de Janeiro - EBA/UFRJ. Doutora em Teatro pela Universidade do Estado do Rio de Janeiro - UNIRIO, com pesquisa sobre Peter Brook e Anton Tchekhov. Publicaçôes recentes: Sobre as formaçôes conceituais do espaço vazio de Peter Brook (Revista Moringa, v. 3, n. 1, 2012); e O tapete e o Théâtre des Bouffes du Nord: "forma essencial" na poética teatral de Peter Brook (Revista O Percevejo Online, v. 4, n. 2, 2012).

E-mail: larissaelias@terra.com.br

Recebido em 07 de novembro de 2012 Aprovado em 29 de dezembro de 2012 